\title{
REPAIR AND RETROFIT OF A ROMAN BRIDGE IN TURKEY
}

\author{
H. SESIGUR ${ }^{1 *}$ AND M. ALABOZ ${ }^{2}$ \\ ${ }^{1}$ Istanbul Technical University Faculty of Architecture Division of Theory of Structures \\ Taskisla, Taksim, 34437, İstanbul, Turkey \\ e-mail: haluk@itu.edu.tr, www.itu.edu.tr (*corresponding author) \\ ${ }^{2}$ ARKE Project Design Company, İstanbul, Turkey \\ email: alaboz.murat@gmail.com
}

Keywords: Historical Structure, Masonry, Roman Bridge, Retrofit

\begin{abstract}
This study assesses the earthquake performance of a historical masonry arch bridge in Aizanoi ancient city, which is located in the mid part of Turkey near Kütahya. Aizanoi was the capital of the territory called Aizanitis, located in the area of Phrygia. Historians agreed that Roman settlement in this area started in $3^{\text {rd }}$ millenium BC. The structure is made of stone and has five arches of $5.40 \mathrm{~m}, 6.70 \mathrm{~m}, 7.30 \mathrm{~m}$ spans. Rise of the arches are varying from $2.70 \mathrm{~m}$ to $3.65 \mathrm{~m}$. Restoration works have completed in 2018. Before the restoration works have been started the bridge was used for vehicles, even for heavy trucks. Today the bridge is using only for pedestrians. After a detailed site investigation, material characterisation and soil tests were performed, ambient vibration test was carried out on site, by placing accelerometers at several points on bridge span to capture dynamic properties of the structure. Different methods such as Frequency Domain Decomposition, SSI were used to extract the experimental natural frequencies, mode shapes, and damping ratios from these measurements. Experimental results were compared with those obtained by the linear finite element analysis of the bridge. Good agreement between mode shapes was observed in comparison, though natural frequencies disagree by 8-10\%. The boundary conditions of the linear finite element model of the bridge were adjusted such that the analytical predictions agree with the ambient vibration test results. According to the total strain crack material model, the calibrated linear FE model was extended into a nonlinear model then Nonlinear Static Pushover analyses of the bridge along longitudinal and transversal directions were performed. Obtained results are in good agreement with previous case studies' results. In order to compare collapse load of the bridge with pushover analysis results, kinematic limit analysis procedure is used to assess longitudinal and transverse seismic capacities. The capacity curves are obtained by means of limit analysis approach. The study is aimed to identify on one hand the horizontal load multiplier that activates the kinematic mechanism, on the other hand the collapse displacement. The numerical results of the structural capacity so found have been compared with the results available in literature and acceptable agreement of the results have been obtained.
\end{abstract}

\section{INTRODUCTION}

The assessment of the condition of historical bridges is an important issue in recent years. This task is particularly difficult when dealing with historical masonry arch bridges due to their 
specificities as use of natural materials, lack of knowledge related to mechanical properties of materials and their large variability, existing damage caused by increasing traffic loads, aging and environmental factors and lack of maintenance. A very important approach is the use of numerical models able to reproduce the structural response, both at serviceability and ultimate limit states. In order to solve this problem several methods and computational tools are available. Different types of constitutive models originate a sequence of models, which allow the analysis to include more complex response effects. The most common idealizations of material behaviour are elastic behaviour, plastic behaviour and nonlinear behaviour. In general linear elastic analyses might not appropriate for masonry structures, namely masonry arch bridges, however, in a first stage of analysis, the hypothesis of linear elastic behaviour can be of great help. A linear analysis requires few input data, being less demanding, in terms of computer resources and engineering time used, when compared with nonlinear methods. Moreover, for materials with low tensile strength, linear analysis can provide a reasonable description of the process leading to the crack pattern.

Plastic analysis, or limit analysis, is concerned with the evaluation of the maximum load that a structure can sustain. The assumption of plastic behaviour implies that, on one hand, the maximum load is obtained at failure and, on the other hand, the material should possess a ductile behaviour. Apparently, this last requirement seems to be unrealizable since the plastic

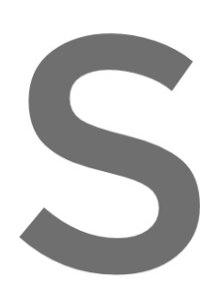
deformations may

compression does not pl strength. Thus, the as\$urt adequate for the analysi powerful method of analys
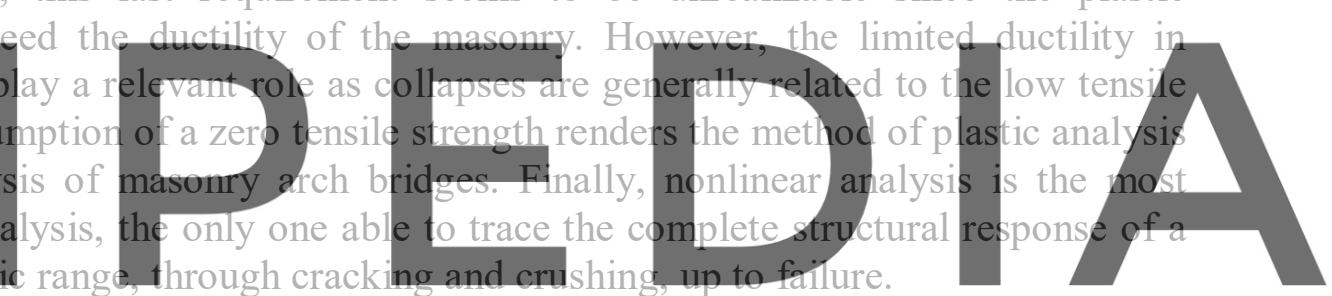

Several procedures have been formulated in last decades in order to predict the behaviour of

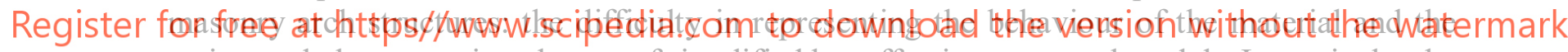
resistant skeleton requires the use of simplified but effective structural models. In particular the assessment could be based commonly on limit analysis [1,2,3] or nonlinear incremental techniques $[4,5,6]$. The kinematic method, based on an adaptation of limit design for masonry structures, has proved to be a conceptually simple and robust procedure to verify the safety of masonry arch bridges under vertical loads. The method can also be applied for seismic assessment, providing a limit of bridge capacity under horizontal loads. Since [7] noted that the plastic theory, initially formulated for steel structures, could also be applied to masonry structures, many studies have focused on limit analysis to assess the vertical load-bearing capacity of single and multi-span masonry arches $[1,8]$ adopted some simplifying assumptions to perform aforementioned analyses: absence of sliding between voussoirs: infinite compressive strength and no tensile resistance of masonry.

With these hypotheses, arch failure occurs when a thrust line can be found, lying wholly within the masonry and representing an equilibrium state for the structure under acting loads, which allows the formation of a sufficient number of plastic hinges to transform the structure into a mechanism. Following Heyman's assumptions, iterative methods to find the geometric safety factor, related to minimum arch thickness under dead and live loads, were proposed by [9]. Several authors have incorporated crushing of masonry, which cannot sustain infinite 
compressive stresses [9,10,11]. Sliding between adjacent blocks was introduced and evaluated by [12], who successfully modelled multi-span brickwork arch bridges. Recent research has been carried out on the application of limit analysis for assessing masonry arches under horizontal (seismic) loads. In particular, research has focused on the longitudinal behaviour of arched structures. Some papers [13] have studied the dynamic response of a single masonry arch under base motion, providing the horizontal acceleration factor. [14] used discrete element modelling to predict the combinations of impulse magnitudes and durations which lead unreinforced masonry arches to collapse, and analysed the impact of rigid blocks over several cycles of motion. [15] examined the activation of semi-global and global mechanisms involving not only local arch failure but also the simultaneous formation of hinges in the arch and at the base of abutments.

\section{STRUCTURAL DEFINITION OF THE BRIDGE}

This study assesses the earthquake performance of a historical masonry arch bridge in Aizanoi ancient city, which is located in the mid part of Turkey near Kütahya. Aizanoi was the capital of the territory called Aizanitis, located in the area of Phrygia. Historians agreed that Roman settlement in this area started in $3^{\text {rd }}$ millenium BC. The structure is made of stone and has five arches of $5.40 \mathrm{~m}, 6.70 \mathrm{~m}, 7.30 \mathrm{~m}$ spans. Rise of the arches are varying from $2.70 \mathrm{~m}$ to

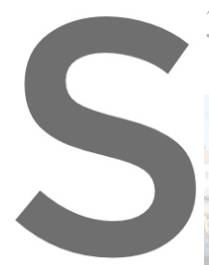
$3.65 \mathrm{~m}$
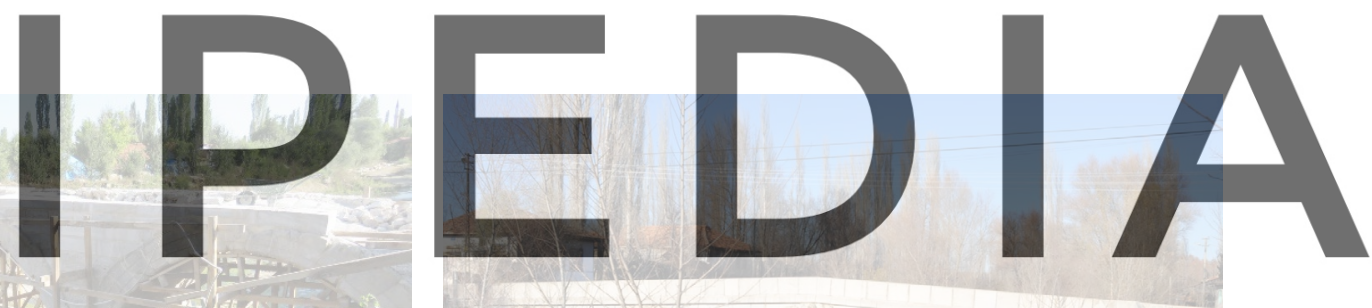

Register for free at https//www.scipedia.com to download the version without the watermark

Figure 1. Pictures taken from during the restoration works

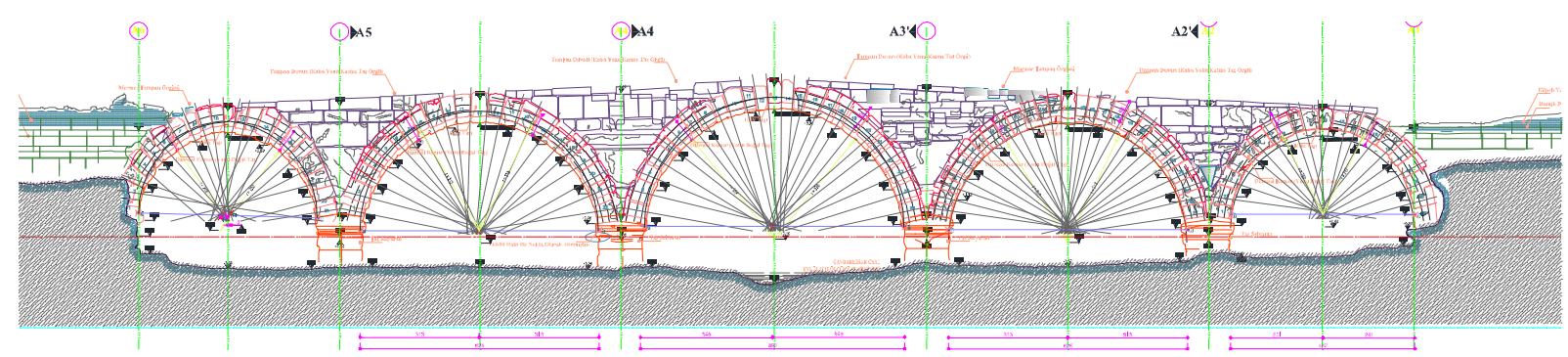

Figure 2. Elevation of the bridge 


\section{ASSESSMENT OF THE STRUCTURAL SYSTEM}

\subsection{Damage mapping}

After surveying studies were completed on site investigation was carried out. During the site visit some damages were observed such as visible cracks on the surface of the abutments, material losses, deterioration and also some detachment of joints.

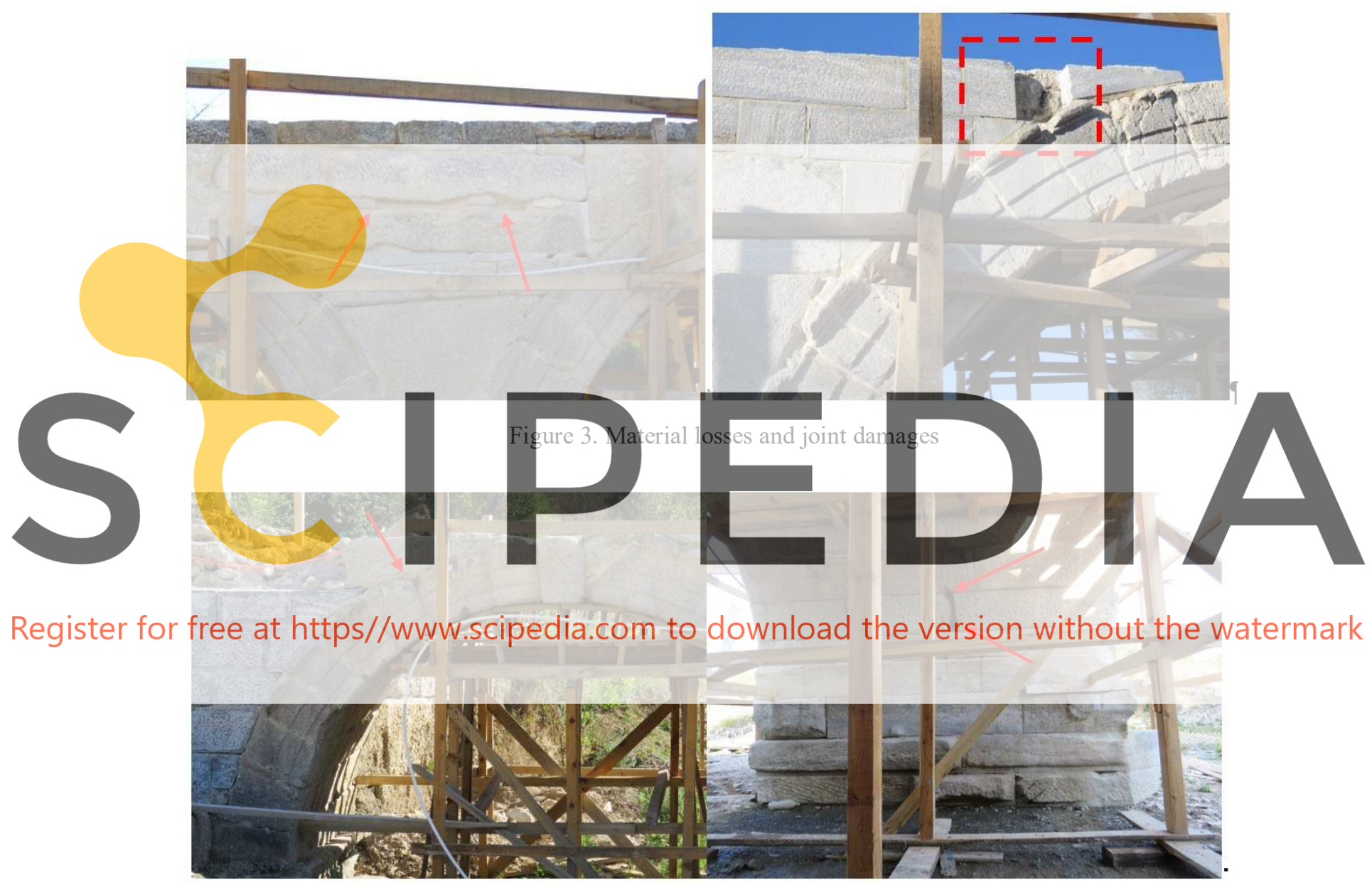

Figure 4. Some damages on joints

\subsection{Structural analysis}

In order to assess the existing vertical and lateral load capacity of the structure and to give possible intervention proposals, the structural and geometrical configurations defined have been modelled using the software DIANA: for masonry structures, the best modelling technique is usually chosen in function of the analysis objective between different modelling strategies and modelling levels such as micro-modelling or macro-modelling. 3D models implementing a macro-modelling approach have been adopted for finite element discretization, where masonry 
was modelled as an homogeneous continuum using six- and eigth-node elements, Figure 5.

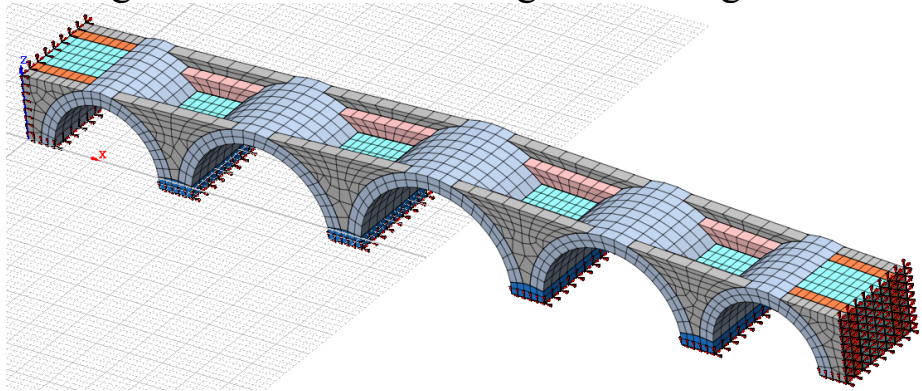

Figure 5. 3D model of the bridge

The Total Strain Crack Model implemented in DIANA was used as constitutive law of masonry. The masonry material exhibits isotropic properties prior to cracking and anisotropic properties after cracking, the cracks being orthogonal to the directions of the main strains. The main materials' mechanical characteristics have been assumed according to literature, considering masonry compressive strength $\mathrm{f}_{\mathrm{c}}$ equal to $5 \mathrm{MPa}$, masonry tensile strength $\mathrm{f}_{\mathrm{t}}$ equal to $0.3 \mathrm{MPa}$ and elastic modulus EM equal to $5000 \mathrm{MPa}$. The filling material has been modelled considering Drucker-Prager constitutive law with an elastic modulus EF equal to 500MPa,

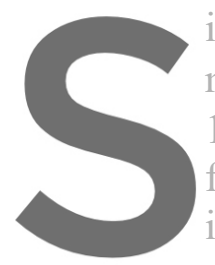
internal friction $\phi=37^{\circ}$ and cohesion o- $10 \mathrm{kPa}[16]$. For both materiats (masonry and filling material) a specific weight $\rho$ of the stone equal to $26.5 \mathrm{kN} / \mathrm{m}^{3}$ $18 \mathrm{kN} / \mathrm{m}^{3}$ and a Poisson ratio $\gamma$ equal to 0.2 for masonry has been considered elasto-plastic in traction. Mode I fract represent the arches' failure mode where the typical four cracking hinges that arise in masonry

Register for free at https//WWW.scipedia.com to download the version without the watermark

\subsection{System identification}

System identification test was carried on under ambient vibration on the bridge to check if the integrity of the structure is satisfied as defined in FEM model as a homogeneous modelling technique. In the process, 4 high accuracies, low noise, 3 axial accelerometers were used. In $100 \mathrm{~Hz}, 10-20 \mathrm{~min}$ records were collected in setups by placing the sensors at 6 locations at top of the bridge, Fig. 6.
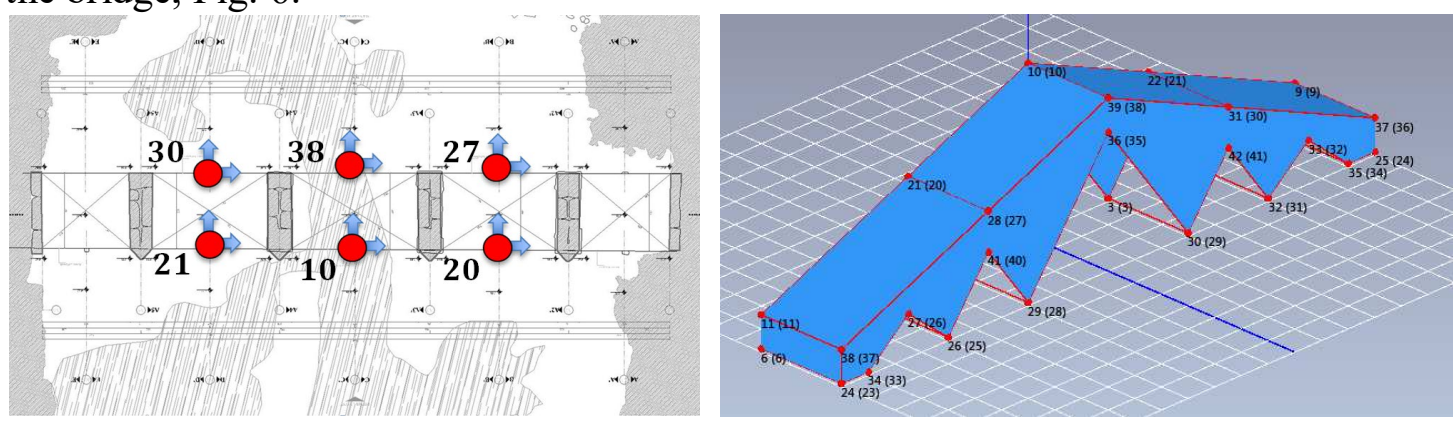

Figure 6. Sensor locations on the bridge 
Natural frequencies were obtained and mode shapes of the bridge, the consistency of the mathematical model was checked. Considering the frequency values, lower frequency in system identification test might be the result of a lower modulus of elasticity. However, the differences are in an acceptable range to rely on FEM model and assumptions to carry on further analysis (Table 1). When the model shapes are compared, the amplitudes of modal displacements obtained by system identification exhibits higher values then FEM model. Peaks in different channels in spectral density graph might be referred to some local discontinuities or irregularities at the inner sections, Fig.7. Mode shapes are depicted in Fig.8.

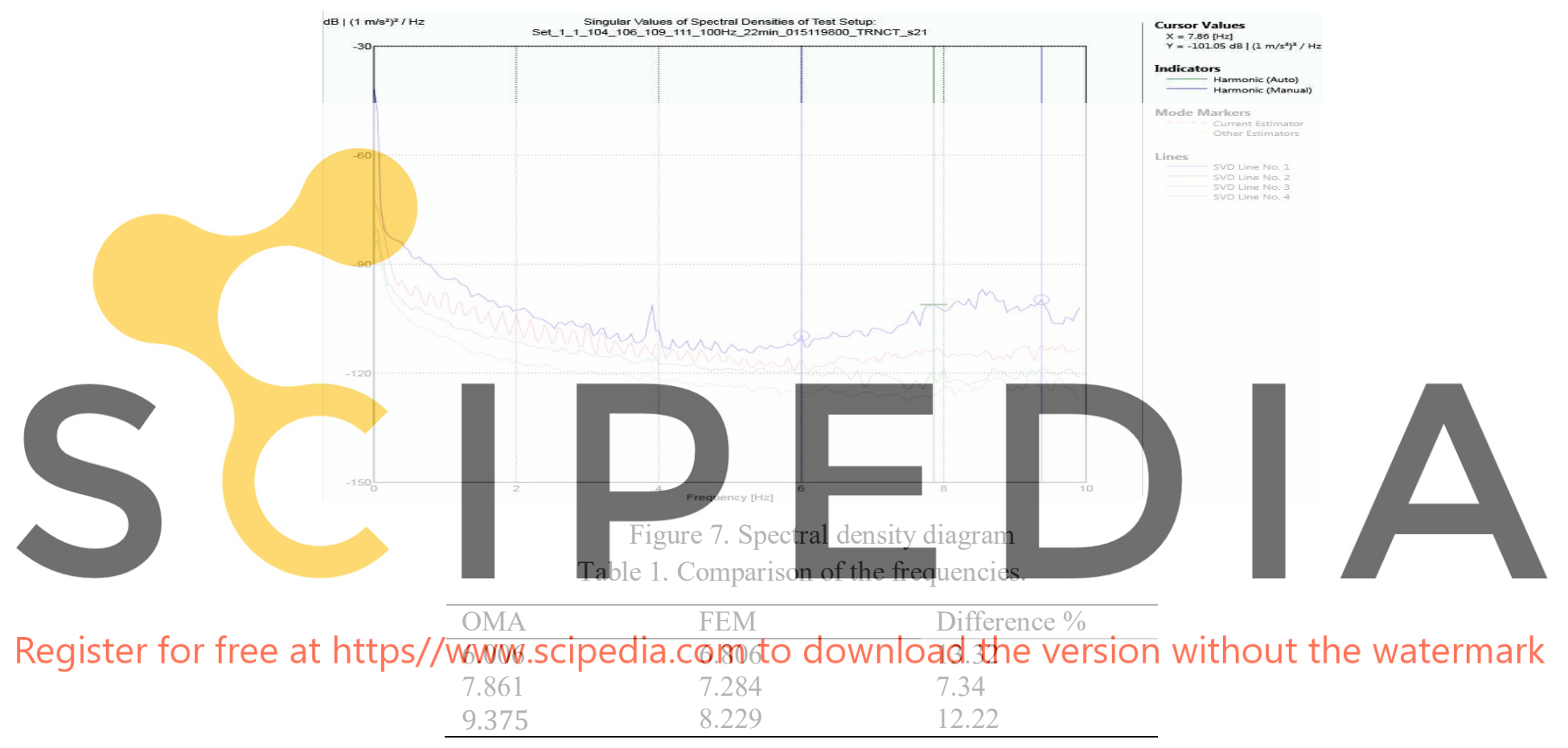

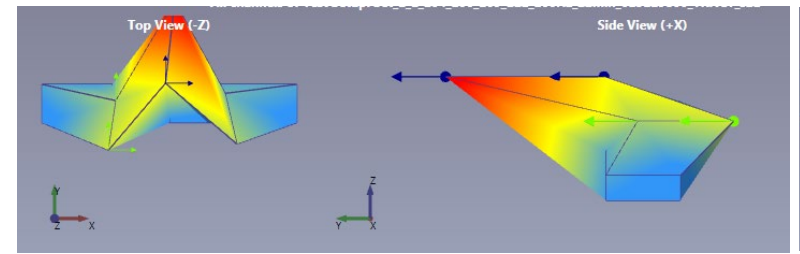

Mode 1. $6.006 \mathrm{~Hz}$

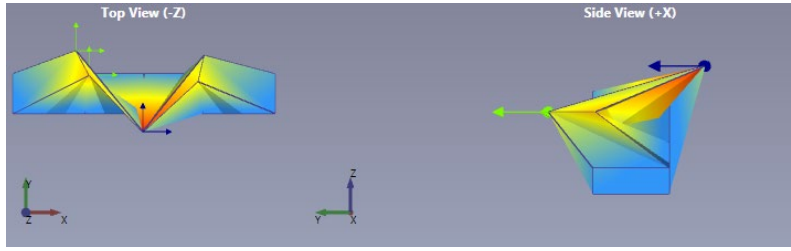

Mode 2.7.861 Hz

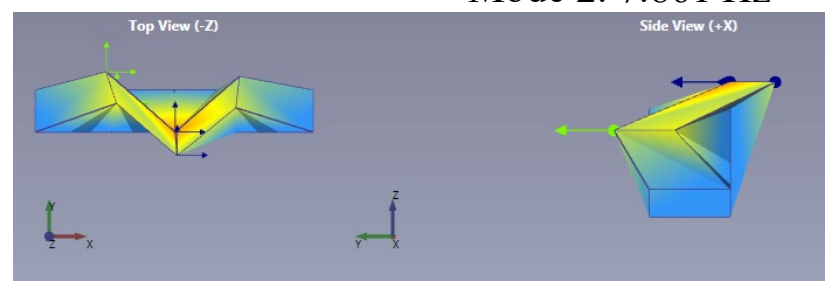

Mode 3. $9.375 \mathrm{~Hz}$

Figure 8. Mode shapes of the bridge 


\subsection{Nonlinear static analyses}

Pushover analyses performed on 3D models have led to the assessment of peak ground acceleration (PGA) which turn the structure into global and local failure mechanisms and to the construction of the relative capacity curves. The results obtained from the analyses carried out on the finite element models in longitudinal and transversal directions have been plotted in terms of ratios between peak ground acceleration corresponding to the occurrence of a local failure mechanism for the arch and PGA values related to the creation of a global mechanism, Fig. 9,10. PGA values have been obtained with N2 method [17] and the spectra type adopted in this work according to Turkish Earthquake Code (2007) for the ultimate limit state $(10 \%$ exceedance probability during 50 years). The failure mechanism substantially depends from the height to width $(\mathrm{H} / \mathrm{B})$ and rise to span $(\mathrm{f} / \mathrm{L})$ ratios, and quite apart from the geometrical dimensions: in some studies, it has been observed that masonry arches with higher $\mathrm{f} / \mathrm{L}$ values are more vulnerable than others characterized by lower f/L ratios. For semi-circular masonry arch bridges, also in the case of slender piers, the four plastic hinges that define the collapse mechanism are generally localized in the arches involving a local failure mode; masonry piers characterized by low H/B values are instead substantially less vulnerable than the slender ones. In transversal direction, failure mechanisms have been identified on the basis of a critical evaluation of the results obtained from the pushover analyses. Capacity curves have been

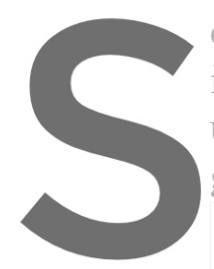
expressed in the interpolated with an els ultimate displacement po ground acceleration $\mathrm{PG}$
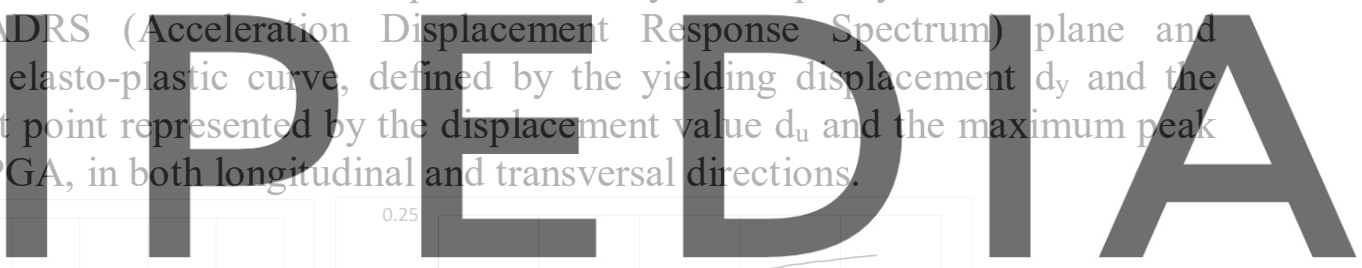

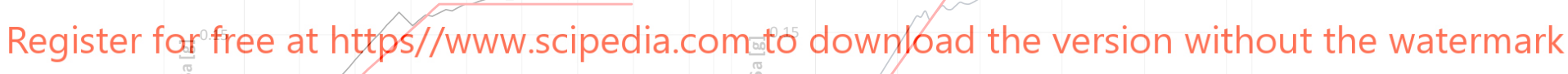
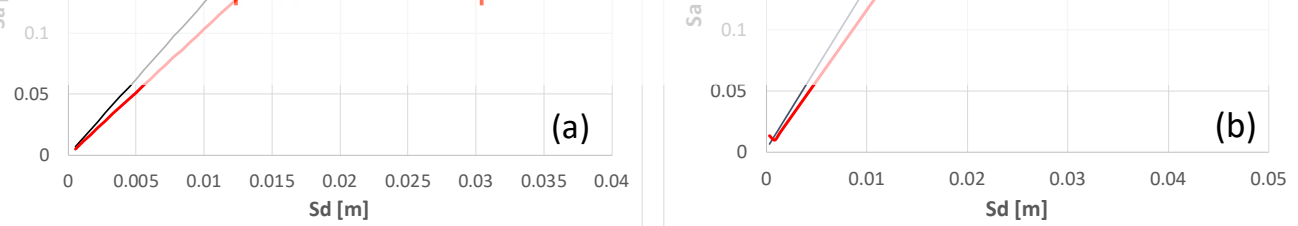

Figure 9. Capacity curve of existing bridge in a) longitudinal direction b)transversal direction
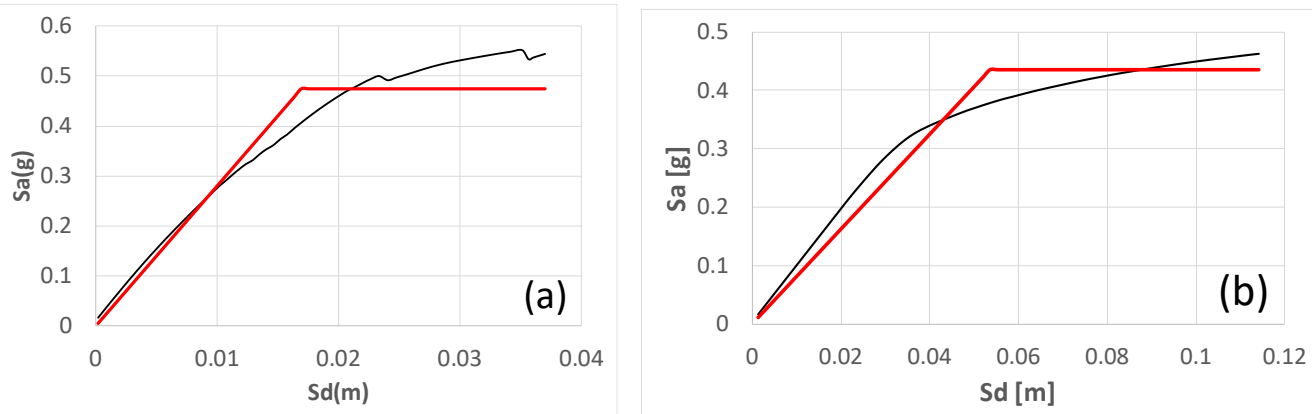

Figure 10. Capacity curve of restorated bridge in a)longitudinal direction b)transversal direction 

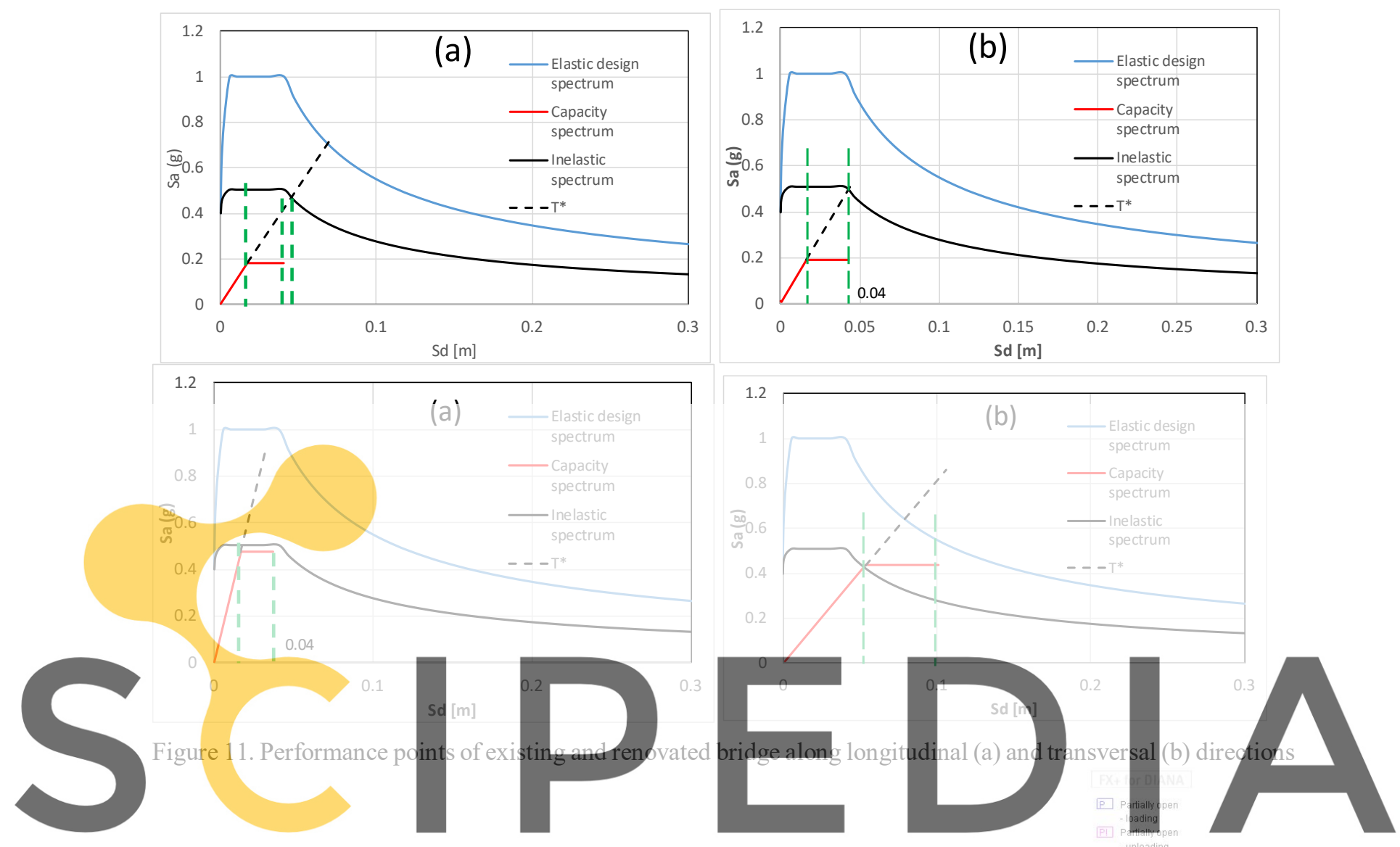

Register for free at https//www.scipedia.com to download the version without the watermark

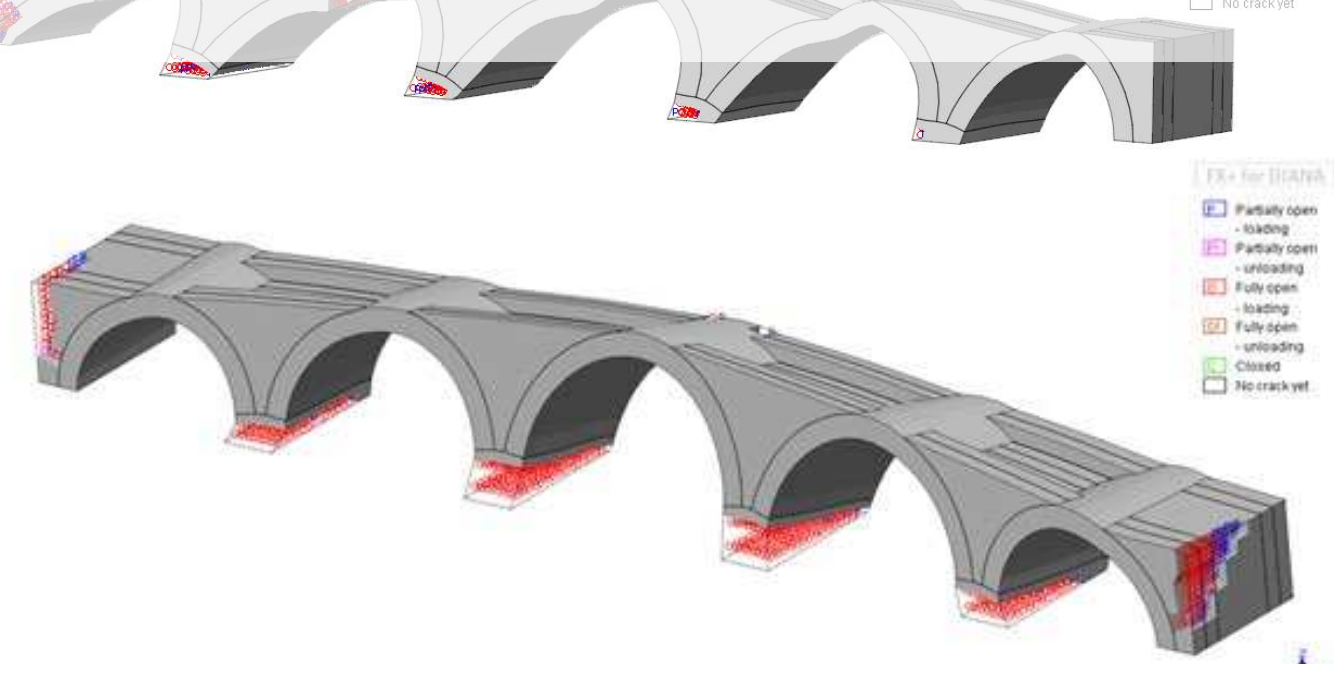

Figure 12. Collapse mechanisms along longitudinal and transversal directions 


\subsection{Limit analysis}

Various specialized analysis programs which rely on the theorems of limit analysis have been developed over years. Currently available tools include ArchieM (Obvis 2007) and ring 2.0 (LimitState 2007b). ArchieM is based on a lower bound line of thrust methodology. The program displays graphically a potential thrust-line for any given load. If a thrust-line cannot be found which lies entirely within the masonry, then the bridge can be considered potentially unsafe. In contrast ring 2.0 uses mathematical optimization to directly identify the collapse state, computing the load factor which, when applied to the specific live load, will lead to collapse.

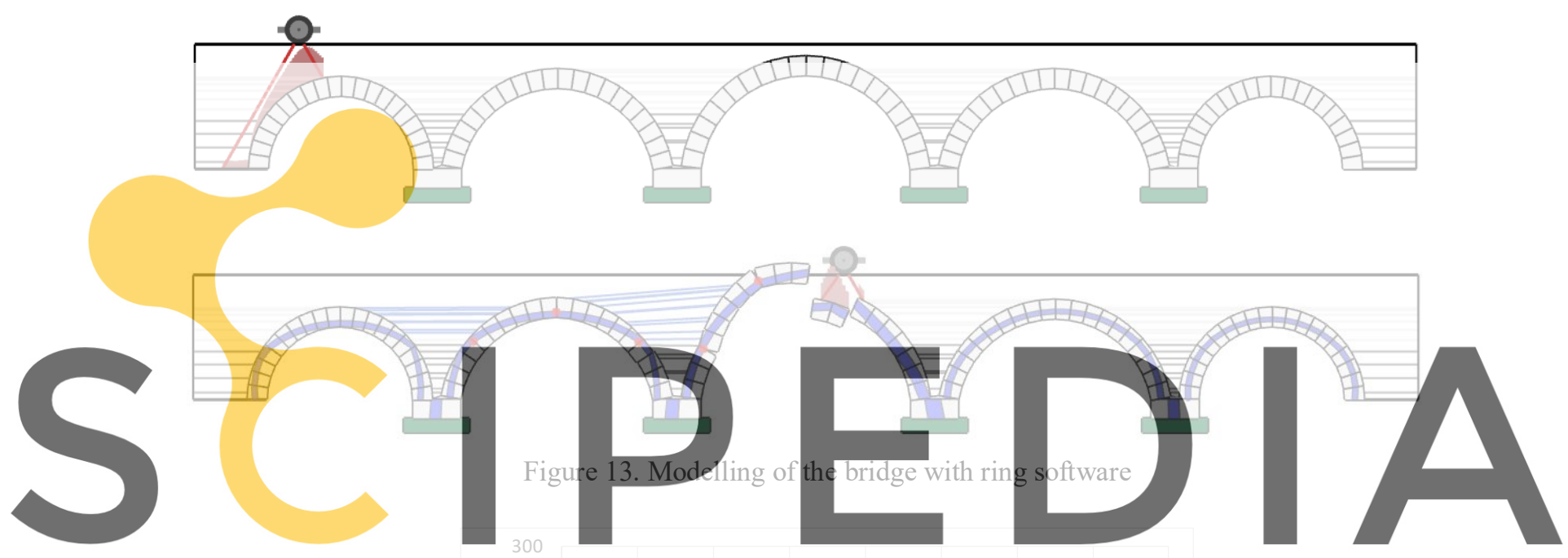

Register for free at https//wwW'scipedfia.com to download the version without the watermark

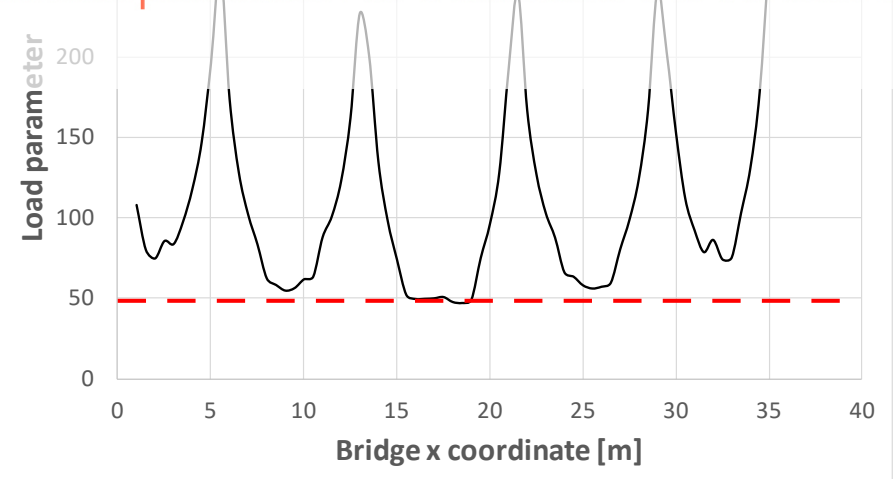

Figure 14. Collapse load of the bridge

Limit analysis with ring software is carried out and the result is obtained as $50 \mathrm{kN}$ for live load which can be determined from Fig. 14. 


\section{CONCLUSIONS}

In this study the earthquake performance of a historical masonry arch bridge is assessed in Aizanoi ancient city, which is located in the mid part of Turkey near Kütahya. Before the restoration works have been started the bridge was used for vehicles, even for heavy trucks. Today the bridge is using only for pedestrians. After a detailed site investigation, material characterisation and soil tests were performed, ambient vibration test was carried out on site, by placing accelerometers at several points on bridge span to capture dynamic properties of the structure. Different methods such as Frequency Domain Decomposition, SSI were used to extract the experimental natural frequencies, mode shapes, and damping ratios from these measurements. Experimental results were compared with those obtained by the linear finite element analysis of the bridge. Nonlinear Static Pushover analyses of the bridge along longitudinal and transversal directions were performed. Obtained results are in good agreement with previous case studies' results. In order to compare collapse load of the bridge with pushover analysis results, kinematic limit analysis procedure is used to assess longitudinal and transverse seismic capacities with a software of ring. The numerical results of the structural capacity so found have been compared with the results available in literature and acceptable agreement of the results have been obtained.
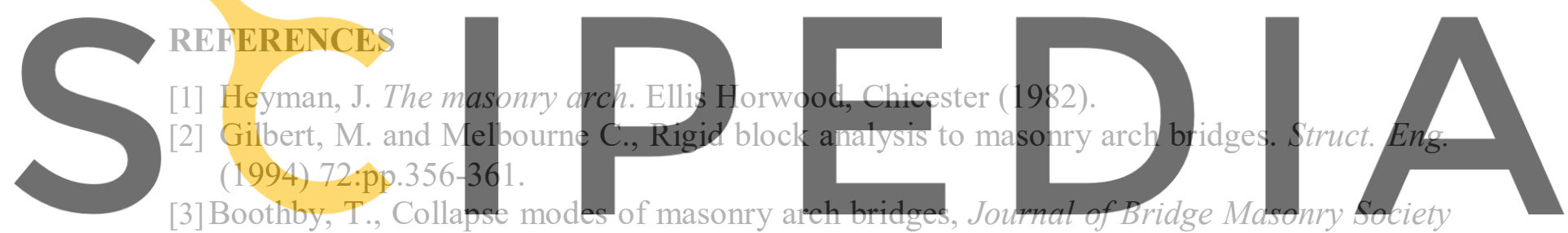

\section{(1995) 9 (2): pp. 62-69.}

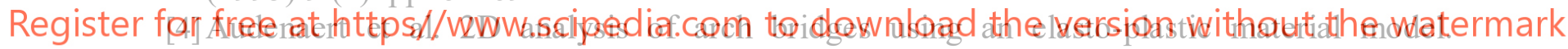
Engineering Structures (2008) 30: pp.845-855.

[5] Brencich, A. and De Francesco, U. Assessment of multi-span masonry arch bridges. Part I: a simplified approach. Part II:examples and applications. Journal of Bridge Engineering ASCE (2004) 9 (6): pp.582-598.

[6] Molins, C. and Roca, P. Capacity of masonry arches and spatial frames. Journal of Structural Engineering (1998) 124:pp.653-663.

[7]Heyman, J. The Stone Skeleton. International Journal of Solids and Structures (1966) 2:pp.249-279.

[8] Gilbert, M. Limit analysis applied to masonry arch bridge: state of the art and recent developments. Proc. $6^{\text {th }}$ international conference on arch bridges, ARCH'07 (2007).

[9] Clemente et al. Limit behavior of stone arch bridges. Journal of Structural Engineering ASCE (1995) 121 (7): pp.1045-1050.

[10] Gilbert, M. On the analysis of multi-ring brickwork arch bridges. Proc. $2^{\text {nd }}$ International conference on arch bridges. (1998).

[11] Clemente et al. Application of limit analysis to stone arch bridges. Proc. $6^{\text {th }}$ International conference on arch bridges ARCH'010. (2010). 
[12] Gilbert, M. and Melbourne, C. Rigid-block analysis to masonry arch bridges. Struct. Eng. (1994) 72: pp.356-361.

[13] Clemente, P. Introduction to dynamics of stone arches. Earthquake Engineering and Structural Dynamics (1998) 27:pp.513-522.

[14] De Lorenzis et al. Failure of masonry arches under impulse base motion. Earthquake Engineering and Structural Dynamics. (2007) 6:pp.2119-2136.

[15] De Luca et al. A simplified procedure for assessing the seismic capacity of masonry arches. Engineering Structures (2004) 26:pp.1915-1929.

[16] Cavicchi, A. and Gambarotta, L. Collapse analysis of masonry bridges taking into account arch-fill interaction. Engineering Structures. (2005) 27:pp.605-615.

[17] Fajfar, P. and Gaspersic, P. The N2 method for the seismic damage analysis of RC buildings. Earthquake Engineering and Structural Dynamics. (1996) 25:pp.23-67. 